Published in final edited form as:

Curr Protoc Neurosci. 2001 May ; CHAPTER: Unit7.1. doi:10.1002/0471142301.ns0701s00.

\title{
Overview of Microdialysis
}

\author{
Toni S. Shippenberg and Alexis C. Thompson \\ NIH/NIDA Intramural Research Program, Baltimore, Maryland
}

The technique of microdialysis enables the monitoring of neurotransmitters and other molecules in the extracellular environment. This method has undergone several modifications and is now widely used for sampling and quantitating neurotransmitters, neuropeptides, and hormones in the brain and periphery. This unit describes the principles of conventional and quantitative microdialysis as well as strategies in designing a dialysis experiment. It establishes the groundwork for the basic techniques of preparation, conduct, and analysis of dialysis experiments in rodents and subhuman primates (UNITS 7.2-7.4). Although the methods described are those used for monitoring CNS function, they can be easily applied with minor modification to other organ systems.

\section{HISTORICAL PERSPECTIVE}

The concept of using of a dialysis bag to collect samples from small interstitial tissue, such as the brain, was first introduced by Bito et al. (1966). Delgado refined the technique, developing the first microdialysis probe in which a solution was slowly perfused through a dialysis bag and carried to a site immediately accessible to the experimenter (Delgado et al., 1972). Ungerstedt greatly improved the design of the microdialysis probe by enlarging the surface area of the dialysis membrane and thus increasing the efficiency of the microdialysis probe in collecting analyte (Ungerstedt and Pycock, 1974; Ungerstedt et al., 1982). The successful use of microdialysis to quantify monoamine levels in neural tissue by Ungerstedt and colleagues during the late 1970s and early 1980s contributed significantly to the worldwide use of the microdialysis method.

A recent Medline search revealed that over 3000 articles involving the use of microdialysis to collect substances from tissue have been published since 1960. The majority have studied the extracellular milieu of neural tissue in the laboratory rat, in particular, to collect samples for the analysis of monoamines and their metabolites. It is perhaps no accident that this technique has been characterized so well and applied so often to the study of monoamines. Monoamines are widely distributed in the nervous system and play an important role in most complex brain functions. The extracellular concentration of monoamines is typically high, of neuronal origin, and concentrated in large nuclei such as striatum and accumbens. The physicochemical characteristics of monoamines are well understood (i.e., hydrophilicity, size, structure), and highly sensitive analytical instruments are available for the quantification of dialysis samples [e.g., electrochemical (EC) detection].

Many types of analytes have been successfully sampled by microdialysis. A number of published reports describe the use of the method to collect samples from a variety of tissues and a number of species. The range of microdialysis applications is illustrated in Table 7.1.1, Table 7.1.2, and Table 7.1.3.

The advantages and limitations of microdialysis techniques have been reviewed in detail (Westerink et al., 1987; Benveniste, 1989; Westerink and Justice, 1991) and are only briefly summarized here. The primary advantage of microdialysis over other in vivo perfusion techniques lies in the construction of the probe. First, the microdialysis probe is smaller than devices used for push-pull or cortical cup perfusion and thus displaces a smaller area of tissue. 
Second, the microdialysis membrane provides a physical barrier between the perfusate and tissue that protects the tissue not only from the turbulent flow of the perfusate but also from high-molecular-weight substances, such as bacteria, that cannot cross the membrane. The perfusate flow rate is lower than that used in other perfusion techniques, and thus the amount of analyte depletion from tissue is less.

Finally, a more precise characterization of the quantity and distribution of an analyte can be achieved using microdialysis because the membrane constrains the flow of perfusate, limiting the underlying mechanisms for analyte transport into the probe, and, as a result of the membrane geometry, generates an evenly distributed area of tissue impacted by the probe. Thus, the processes of microdialysis can be well defined mathematically to yield predictions about the characteristic distribution and activity of an analyte of interest (Morrison et al., 1991). Similar advantages do not hold when comparing microdialysis to in vivo voltammetry. Unlike voltammetry, however, the microdialysis technique is not limited to the sampling of electroactive substances. Once a microdialysis sample is collected, any analytical technique may be used to quantify the analyte of interest. Furthermore, for electroactive substances, lower concentrations are detectable using microdialysis than in vivo voltammetry.

Although the microdialysis technique has advantages over other techniques, it also has disadvantages. First, microdialysis has limited time resolution ( $\geq 1 \mathrm{~min}$; more typically, 10-min collection periods are employed) in comparison to voltammetry $(<1 \mathrm{~min})$. Second, the dialysis process creates an area around the probe in which all solutes capable of crossing the probe membrane are depleted. Changes in the neurochemical milieu may affect basal levels and/or the pharmacological responsiveness of the substance under study. It is important to note, however, that Sam and Justice (1996) showed that basal levels of dopamine (DA), in the striatum, are unaffected by variations in the amount of non-DA solute depleted around the probe. Third, low-molecular-weight solutes contained in the perfusate may diffuse into the interstitial space and artificially change the level or activity of the analyte of interest. For example, failure to provide appropriate concentrations of $\mathrm{Ca}^{2+} \mathrm{Or} \mathrm{Na}^{+}$ions in the perfusate can dramatically alter basal levels of neurotransmitters (Westerink et al., 1988; Moghaddam and Bunney, 1989; Osborne et al., 1991). Fourth, the microdialysis membrane occupies space of a particular dimension and length. Thus, use of the microdialysis technique is limited to areas large enough and long enough to surround the microdialysis probe. The smallest probe is still relatively large compared to many nuclei within the central nervous system. Finally, the quantity of analyte collected by microdialysis most often represents a fraction of the actual extracellular concentration because at most flow rates (i.e., $>0.1 \mu \mathrm{l} / \mathrm{min}$ ) the rate of analyte removal from the inside of the probe is higher than the rate of analyte replacement to the probe membrane surface.

This last limitation requires additional comment as the search for the proper mathematical expression of these differences has led to some unanticipated conclusions regarding the interpretation of microdialysis data. At usual perfusate flow rates (e.g., $1 \mu \mathrm{l} / \mathrm{min}$ ), the ratio, or extraction fraction, between the actual extracellular concentration of an analyte and the dialysate concentration of that same analyte is typically less than $40 \%$. (The extraction fraction is otherwise known as relative recovery or probe efficiency.) Because flow rate is inversely related to extraction fraction (Zetterstrom et al., 1988; Wages et al., 1986), it is possible to reduce the flow to a rate suitable to achieve near equilibrium. However, the sample collection volume and collection period at these very low perfusate flow rates are either insufficient or inappropriate to test most hypotheses.

Several groups have attempted to characterize and quantify the extraction fraction. An understanding of the source of diffusivity during dialysis has greatly aided this aim. When extraction fraction is low, as is typically the case, the greatest source of resistance to diffusion 
occurs in the tissue. Tissue resistance differs for each analyte under consideration and, in turn, is influenced by neurochemical processes that affect analyte supply and degradation. As a result, experimental manipulations that modify these neurochemical processes may also modify extraction fraction and confound interpretation of changes in dialysate concentration. (This means that changes in dialysate concentration do not only mirror changes in extracellular concentration, but will also reflect changes in extraction fraction and/or extracellular concentration.) Thus, the study of the diffusional and/or convective processes underlying analyte sampling by microdialysis (or solute delivery by the microdialysis probe) has been developed (e.g., quantitative microdialysis) to determine in vivo extraction fraction and the proportional relationship between dialysate and extracellular concentrations of an analyte under study. The theoretical and empirical findings to date are discussed in detail in the following three sections.

\section{DESCRIPTION OF THE MICRODIALYSIS PROCESS}

All microdialysis probes are composed of a length of tubular dialysis membrane through which a solution, usually devoid of the analyte of interest, is constantly perfused. The dialysis membrane is semipermeable and permits free transport of some but not all solutes. Permeability is typically limited to small molecules with molecular masses less than 20,000 Da. Once the probe is inserted into an external medium (i.e., tissue), substances at the outside surface of the dialysis membrane that are present in lower concentrations in the perfusate diffuse through the membrane into the perfusate. The perfusate slowly flows through the length of the dialysis probe into the outflow tubing where it can be collected for subsequent analyte quantification.

The presence of the microdialysis probe impacts on the external medium surrounding it. As low-molecular-weight solutes are removed from the external medium by the microdialysis probe, a zone around the probe becomes depleted of solute. Depletion is not complete because the external medium is continuous and large, so that the solutes can be partially replaced by diffusion from areas of higher concentration that are undisturbed by the probe. However, it is probable that the supply of a particular solute will not equal its loss, and therefore the concentration of the solute in the area immediately adjacent to the probe membrane will be reduced. Therefore, a description of the microdialysis process should include an account of the changes in concentration of the analyte in the tissue around the probe. Of particular interest will be the difference in concentration between the undisturbed tissue and the dialysate and the size of the area of analyte depletion (penetration distance). This information will aid in the interpretation of the results from a microdialysis experiment by providing a measure of probe efficiency that makes it possible to calibrate the concentration of the analyte in the dialysate with respect to its extracellular concentration and to identify the anatomical site from which the microdialysis sample is collected (i.e., to determine how far away from the probe it is).

The underlying process driving analyte transport during microdialysis is generally accepted to be diffusion. This assumption has been challenged by Bungay and Gonzales (1996) who showed that ultrafiltration, as a result of osmotic pressure differences across the probe membrane, contributed significantly to the transfer of ethanol from the perfusate into tissue during a microdialysis experiment. The parameters of the experiment including flow rate, inflow tube length, and tube diameter and the chemical characteristics of ethanol likely contributed to the occurrence of ultrafiltration. Additional mathematical considerations are necessary to account for ultrafiltration during analyte transport. Because, however, ultrafiltration is not expected to occur during most microdialysis experiments, it is not included in the mathematical discussion below. The presence of ultrafiltration during microdialysis can be identified by determining if fluid volume is lost during dialysis. Diffusion of a given analyte involves transport of that analyte down its concentration gradient from the "undisturbed" tissue into the perfusate. An analysis of the slope of the concentration gradient, the radial distance 
over which the concentration gradient occurs, and the net change in concentration of the analyte (extraction fraction) over the course of the concentration gradient can be used to describe the transport of analyte during microdialysis. It is important to note that the concentration gradient is influenced not only by the physical attributes of the analyte (i.e., molecular weight, hydrophobicity, and tertiary structure), but also by the physical composition of the medium in which transport occurs. Therefore, a complete characterization of the transport of an analyte during microdialysis involves a description of the concentration gradient in the external medium (e.g., tissue), the concentration gradient across the membrane, and the concentration gradient across the annular width of the microdialysis probe.

\section{PRINCIPLES UNDERLYING MICRODIALYSIS}

During microdialysis, substances move from an area of higher concentration through the probe to an area of lower concentration. The direction of movement, into or out of the microdialysis probe, is set by the experimenter, who biases the procedure so that the concentration of the analyte under study is higher on one side of the probe membrane. In this way, the technique is used either to sample a substance from an external solution or to deliver a substance to the external solution. The extraction fraction (i.e., probe efficiency or relative recovery) defines the proportional difference in concentration between the highest concentration of substance and the lowest concentration of the substance (e.g., "undisturbed" extracellular concentration versus dialysate concentration as illustrated in Fig. 7.1.1). Knowing the relative recovery is essential in estimating the external concentration of a substance from the concentration of that same substance in the dialysate. In addition, for practical reasons, knowing relative recovery makes it easier to choose the flow rate and collection period that will supply samples of sufficient concentration for detection.

Relative recovery can be determined empirically if the external concentration of the substance is known or directly measurable. Such is the case for in vitro preparations, in which direct measurement of the substance in the external solution is easily accomplished (see UNIT 7.2 for microdialysis in vitro). An empirical determination of in vivo recovery can also be obtained by using one of several quantitative microdialysis methods described in the next section. However, many microdialysis experiments have used in vitro relative recovery to transform in vivo dialysate levels to estimates of extracellular concentration. This latter method of estimating extracellular concentration of an analyte has proved to be imprecise (Glick et al., 1994), mainly because diffusion in tissue differs significantly from diffusion in a solution (Nicholson and Rice, 1986).

A number of mathematical models have been developed to describe the processes governing analyte transport during in vitro and in vivo microdialysis (Amberg and Lindefors, 1989; Benveniste, 1989; Lindefors et al., 1989b; Bungay et al., 1990). These models provide testable hypotheses regarding how and why relative recovery in tissue deviates from relative recovery in solution and provide the basis with which to understand how dialysate levels of an analyte relate to extracellular concentration. A brief theoretical treatment of the microdialysis process is given below.

The physical laws governing diffusion and convective processes describe the movement of substances across a medium in which a concentration gradient exists (for discussion of this subject, see Friedman, 1986). The description of analyte transport during microdialysis has been limited to the consideration of diffusive processes alone, as the impact of convective processes during microdialysis, such as osmotic and/or hydrostatic pressure differences across the membranes, are thought to be negligible (Benveniste, 1989; Bungay et al., 1990). The rate of analyte transport by diffusion can be described mathematically by Fick's law of diffusion which states that: 


$$
J=-D \frac{\Delta c}{\Delta r}
$$

where $J$ is the flux (i.e., moles of solute transported over the area of diffusion), $D$ is the diffusion coefficient, $\Delta c$ is the change in concentration of the analyte over the area of diffusion, and $\Delta r$ is the small length over which diffusion occurs. The assumptions underlying this expression are that the transport of the analyte occurs through an ideal solution that is homogeneous in composition and that the concentration gradient is at steady state. Of course, these assumptions are not met during microdialysis. Therefore, the expression of flux must be altered to reflect analyte diffusion in a microdialysis preparation.

Consider first the composition of the solution or medium through which diffusion occurs. During microdialysis, substances move across three media, each of distinct composition: perfusate, membrane, and external medium (i.e., tissue). The factors that guide diffusion will vary in each medium, and thus the concentration profile will differ. Therefore, the diffusional characteristics of a substance in each medium must be considered separately. An expression of flux that allows for the consideration of analyte transport across several media is given by the following equation:

$$
J=\frac{\Delta C_{1-3}}{R_{1}+R_{2}+R_{3}}
$$

Here transport is expressed as resistance $R$ instead of diffusivity $D$ because resistances, in series, can be added (Friedman, 1986). In this equation the subscripts 1, 2, and 3 refer to the three media over which diffusion occurs (external medium, membrane, and perfusate), $\Delta C_{1-3}$ is the overall concentration difference between the phases, and $R_{x}$ is the resistance to diffusion, or inverse permeability, of the solute in medium $x$ of $R_{x}$. The form of the expression can be modified to account for the way in which the medium of each phase deviates from the ideal solution.

Bungay et al. (1990), who have provided the most comprehensive discussion of analyte transport during microdialysis under steady-state conditions, use the expression of mass transport resistance to describe the proportional difference in analyte concentration between the undisturbed external medium and the microdialysis probe perfusate $\left(E_{\mathrm{d}}\right)$. Solving the mass transport resistance equation, above, for the appropriate geometry and boundary conditions, $E_{\mathrm{d}}$ under steady-state conditions is given by:

$$
E_{\mathrm{d}}=\frac{C_{\mathrm{out}}-C_{\mathrm{in}}}{C_{\mathrm{ext}}-C_{\mathrm{in}}}=1-\exp \left[-\frac{1}{Q_{\mathrm{d}}\left(R_{\mathrm{d}}+R_{\mathrm{m}}+R_{\mathrm{e}}\right)}\right]
$$

where $Q_{\mathrm{d}}$ is the perfusate flow rate and $R_{\mathrm{d}}, R_{\mathrm{m}}$, and $R_{\mathrm{e}}$ are the resistances for the dialysate, membrane, and external medium, respectively. $C_{\text {out }}$ is the concentration of solute in the dialysate sample, $C_{\mathrm{in}}$ is the concentration of solute in the perfusate (typically zero for conventional microdialysis experiments), and $C_{\mathrm{ext}}$ is the concentration of solute in tissue undisturbed by the action of the microdialysis probe.

$E_{\mathrm{d}}$ provides a measure of probe efficiency. It is the correction factor by which to transform analyte concentration in dialysates to extracellular concentration. Changes in $E_{\mathrm{d}}$ will occur when there are changes in diffusional resistance or changes in flow rate. For small hydrophilic substances studied so far, the greatest source of resistance during microdialysis has been found to be tissue ( $R_{\mathrm{e}}>R_{\mathrm{m}}>R_{\mathrm{d}}$; Bungay et al., 1990). Changes in the processes underlying differential resistance in tissue will change $E_{\mathrm{d}}$.

Changes in $E_{\mathrm{d}}$ appear simply as increases or decreases in dialysate concentration of the analyte, and do not necessarily mean that extracellular concentration has changed. Decreased $E_{\mathrm{d}}$ may 
mean reduced relative recovery and/or increased radial distance between undisturbed tissue and the probe. Increased $E_{\mathrm{d}}$ may mean that the source of undisturbed analyte was either closer to the probe and decreased $E_{\mathrm{d}}$ may mean that the undisturbed tissue was farther away. An increase in $E_{\mathrm{d}}$ would increase relative recovery and reduce the radial distance between the undisturbed tissue and the probe. In most conventional microdialysis reports, an underlying assumption is that $E_{\mathrm{d}}$ remains unchanged over the course of dialysate collection, so any change in dialysate concentration is interpreted as a change in extracellular concentration (or release of the analyte). Increasing evidence suggests that this assumption is not always valid (Justice, 1993). A theoretical consideration of the factors affecting tissue resistance, and therefore $E_{\mathrm{d}}$, is presented below.

The general expression proposed by Bungay et al. (1990) to describe resistance in a microdialysis preparation is:

$$
R=\frac{\Delta r}{D_{\text {eff }} \phi S}
$$

where $r$ is the length over which diffusion occurs, $D_{\text {eff }}$ is the (effective) diffusion coefficient corrected for the complex geometry of the extracellular space, $\phi$ is the volume fraction, and $S$ is the surface area of the probe. Therefore, we can expect that resistance to analyte transport in each medium can be determined by finding the distance over which the concentration gradient occurs (e.g., from the boundary of the "undisturbed" area in the external solution to the outer boundary of the membrane) and dividing that distance by the product of the volume fraction (e.g., 1.0 for water), surface area (e.g., of the membrane), and effective diffusion coefficient. The specific mathematical description of resistance in each medium will also contain elements that specify the way in which diffusion in that medium deviates from diffusion in an ideal solution.

Specific expressions for diffusional resistance in the membrane, perfusate, and tissue are detailed in Bungay et al. (1990). The parameters (i.e., $\Delta r, D_{\text {eff }}$ ) needed to solve the resistance equation for the membrane and the perfusate can be determined empirically. Further, it is generally expected that diffusional resistance in the membrane and perfusate is not concentration dependent and is unaffected by any experimental manipulation. Therefore, $R_{\mathrm{m}}$ and $R_{\mathrm{d}}$ should remain constant between and within experimental groups and can be determined independently in a solution. The calculation of tissue resistance is complicated by the fact that both $\Delta r$ and $D_{\text {eff }}$ are unknown and not easily measured. The distance over which the concentration gradient develops, propagating from the probe into the tissue, is inversely related to diffusivity and directly related to the diffusional resistance of the analyte in tissue: as diffusional resistance of an analyte increases, the area over which the concentration gradient develops increases.

Resistance in tissue is significantly increased by the presence of impermeable cell membranes because of the reduced fluid volume available for diffusion (the extracellular space is estimated to be $20 \%$ of the total volume in the brain) and increased complexity in the diffusional path (Nicholson and Rice, 1986). Both factors slow diffusion and increase the $R_{\mathrm{e}}$. In addition, for endogenous substances, generation and removal of the substances are distributed throughout the tissue, regulated by multiple physiological mechanisms, and subject to change as a result of experimental manipulation. To determine the concentration profile of the analyte radiating from the probe in tissue, we must solve the mass balance equation which accounts for all factors that affect diffusion in tissue, including the generation and degradation of the analyte.

Consider the general differential mass balance equation proposed by Bungay et al. (1990) to describe the extracellular concentration of an analyte in a differential element at time $t$ : 


$$
\begin{gathered}
\frac{\partial c_{\mathrm{e}}=D_{\mathrm{eff}}}{\partial t} \frac{1}{r} \frac{\partial}{\partial r}\left[r \frac{\partial C_{\mathrm{e}}}{\partial r}\right]+\left(k_{\mathrm{pe}} C_{\mathrm{p}}-k_{\mathrm{ep}} C_{\mathrm{e}}\right) \\
+\left(k_{\mathrm{r}} C_{\mathrm{i}}-k_{\mathrm{u}} C_{\mathrm{e}}\right)-k_{\mathrm{m}} C_{\mathrm{e}}
\end{gathered}
$$

where $C_{\mathrm{p}}, C_{\mathrm{e}}$, and $C_{\mathrm{i}}$ are the concentrations of analyte in plasma and in extracellular and intracellular compartments, respectively. In this equation, $k_{\mathrm{m}}$ is a rate constant for irreversible metabolism, $k_{\mathrm{pe}}$ and $k_{\mathrm{ep}}$ are the rate constants for analyte transport between the extracellular fluid and plasma, and $k_{\mathrm{r}}$ and $k_{\mathrm{u}}$ are the rate constants for transport between the extracellular and the intracellular compartments by release $\left(k_{\mathrm{r}}\right)$ and uptake $\left(k_{\mathrm{u}}\right)$. The components of the differential mass balance equation are intended to describe all factors that affect the concentration profile of the analyte with the following assumptions: metabolism is linear; tissue binding is rapid and linear; tissue diffusion occurs mainly through the extracellular space; the sampled substance may enter or leave tissue by transport into microvessels that are uniformly distributed in tissue; no sources or sinks for the substance exist in the dialysis membrane; and axial diffusion in the perfusate is minor (Bungay et al., 1990; Morrison et al., 1991).

An important assumption in the above mass balance equation is that terms for analyte degradation are dependent on the extracellular concentration (terms containing $k_{\mathrm{u}}, k_{\mathrm{m}}$, and $k_{\text {ep }}$ ), whereas the terms for analyte generation are dependent on intracellular concentration (i.e., terms containing $k_{\mathrm{pe}}$ and $k_{\mathrm{r}}$ ). This means that the analyte depletion caused by the probe will affect the analyte degradation but not the analyte generation in tissue falling within the depletion zone (the area defined by $r$ in previous equations). The concentration profile described by the solution of the mass balance equation will provide a measure of probe efficiency-giving information on the relative loss of analyte concentration between the undisturbed tissue and the probe as well as the area over which the concentration profile will change the efficiency of the probe (relative recovery and penetration distance).

As mentioned above, it is assumed in the mass balance equation that terms for analyte degradation are dependent on the extracellular concentration, whereas terms for analyte generation are dependent on intracellular concentration, meaning that the analyte depletion caused by the probe affects degradation, but it does not affect the generation of the analyte in tissue located within the depletion zone. Any external manipulation that changes the rate of degradation will change the steady state concentration profile (slope and distance) and, in turn, the efficiency of the probe $\left(E_{\mathrm{d}}\right)$. The direction of change follows directly-increases in analyte clearance increase probe efficiency while decreases in analyte clearance decrease probe efficiency.

The spatial resolution of the probe, or penetration distance $(\Gamma)$, also changes when the rate of analyte clearance changes. This relationship can be expressed as (Bungay et al., 1990):

$$
\Gamma=\sqrt{\frac{D_{\mathrm{eff}}}{k_{\mathrm{ep}}+k_{\mathrm{m}}+k_{\mathrm{u}}}}
$$

where $k_{\mathrm{ep}}$ is the first-order rate constant representing efflux to the microvasculature, $k_{\mathrm{m}}$ is the first-order rate constant representing irreversible extracellular metabolism, and $k_{\mathrm{u}}$ is the firstorder rate constant representing the effect of uptake. $\Gamma$ is used here to define $\Delta r$. This shows that the penetration depth of the concentration gradient induced by the probe is reduced as these rate constants increase. Thus, as the rate of analyte clearance increases, the penetration depth, $\Gamma$, decreases and resistance, $R_{\mathrm{e}}$, increases.

Two important predictions arise from the theoretical consideration of tissue resistance. First, it suggests that any experimental manipulation that changes the rate of analyte clearance will also change $E_{\mathrm{d}}$. Therefore, when the experimental manipulation impacts on analyte clearance, changes in dialysate concentration of the analyte under study will reflect not only changes in 
extracellular concentration but also a change in analyte clearance. (Note that these changes may be in opposite directions. An increase in transmitter uptake would increase $E_{\mathrm{d}}$ but decrease extracellular concentration.) Second, it suggests that the penetration depth of the concentration gradient in tissue will be analyte dependent and potentially variable under conditions when the experimental manipulation modifies analyte clearance. This may be a limiting factor in instances in which small areas of tissue are being sampled (e.g., brain nuclei) in that the "undisturbed tissue" may be outside the area of interest. Note that for substances such as neurotransmitters, which are tightly regulated, clearance rates tend to be high and therefore penetration depths shallow (see Bungay et al., 1990, and Dykstra et al., 1992, for more discussion).

Theoretical consideration of the processes underlying diffusion during microdialysis has advanced greatly and provided new insight into the complexities of interpreting microdialysis data. Additional discussion is available in the reports by Bungay et al. (1990) and Morrison et al. (1991) and in reviews by Justice (1993) and Parsons and Justice (1994). The report by Morrison et al. (1991) extends the mathematical model derived by Bungay et al. (1990) to the transient condition. Empirical evaluation of these theoretical constructs has principally come from Justice and colleagues. They have shown that pharmacological manipulations which specifically affect the rate of analyte clearance of monoamines and acetylcholine will change $E_{\mathrm{d}}$ in the predicted direction (Parsons and Justice, 1992; Cosford et al., 1994; Smith et al., 1992; Vinson and Justice, 1997; see also Bruhn et al., 1995). In general, it is advisable to use methods of microdialysis that provide in vivo estimates of relative recovery, particularly when group differences in the rate of analyte clearance are suspected and/or recovery is low. In this way, it will be possible to weight dialysate levels by in vivo recovery to test hypotheses regarding extracellular concentration. Finally, an important outcome from the theoretical treatment of the underlying processes guiding microdialysis is that it is possible to use in vivo recovery, $E_{\mathrm{d}}$, as an index of the rate of analyte clearance (Bungay et al., 1990; Justice, 1993; Bruhn et al., 1995).

\section{EMPIRICAL METHODS FOR DETERMINING IN VIVO RELATIVE RECOVERY}

Estimates of in vivo probe efficacy (extraction fraction, $E_{\mathrm{d}}$ ) are important for two purposes. First, knowledge of in vivo $E_{\mathrm{d}}$ provides a way of accurately converting dialysate levels to extracellular concentration and, thus, serves as a calibration tool. Second, as discussed above (see Principles Underlying Microdialysis), when $E_{\mathrm{d}}$ is low, changes in the in vivo $E_{\mathrm{d}}$ parallel changes in the resistance of tissue to analyte diffusion. Changes in tissue resistance, in turn, may reflect underlying differences in the metabolism and clearance of the analyte (Justice, 1993; Cosford et al., 1996; Vinson and Justice, 1997).

In early studies, estimates of in vivo $E_{\mathrm{d}}$ were obtained from measurement of in vitro $E_{\mathrm{d}}$. However, it was soon recognized that the main source of resistance to diffusion during microdialysis arises from the external medium (Jacobson et al., 1985; Benveniste, 1989) and not the dialysis membrane. Therefore, estimates of $E_{\mathrm{d}}$ by in vitro calibration were inaccurate. Several groups have developed empirical methods to directly determine in vivo $E_{\mathrm{d}}$ (Jacobson et al., 1985; Lonnroth et al., 1987, 1989; Larsson, 1991). The basic designs of these methods are described below. In addition, the use of in vitro assays to estimate in vivo $E_{\mathrm{d}}$ is reconsidered.

\section{Difference Method}

The difference method described in UNIT 7.2 for determining extracellular concentrations of analytes will also yield an estimate of the in vivo $E_{\mathrm{d}}$. It is the slope of the linear regression that describes the dialysate concentration of the analyte under study as a function of experimentercontrolled variations in perfusate analyte concentration. The net difference between the perfusate concentration and the dialysate concentration of the analyte is assumed to result solely 
from the gain or loss of analyte by diffusion across the microdialysis probe membrane. The direction of diffusion (into or out of the probe) is dictated by the undisturbed tissue concentration and could be either a gain of analyte (if the perfusate concentration is lower than the tissue concentration) or a loss of analyte (if the perfusate concentration is greater than the tissue concentration). In this approach, referred to as the variation in concentration method (Justice, 1993; Parsons and Justice, 1994), analysis is accomplished by perfusing several concentrations of the analyte of interest through the dialysis probe $\left(C_{\mathrm{in}}\right)$ in random order and determining the net change in perfusate concentration after dialysis $\left(C_{\text {in }}-C_{\text {out }}\right)$, where $C_{\text {out }}$ is the dialysate concentration for each $C_{\mathrm{in}}$. The slope defined by the linear regression equation describing $C_{\text {in }}-C_{\text {out }}$ (net change) as a function of $C_{\text {in }}$ (starting perfusate concentration) provides the proportional difference between dialysate concentration and the undisturbed tissue concentration of analyte ( $C_{\text {ext }}$, the "undisturbed" tissue concentration). This proportion, the extraction fraction, describes the transport of analyte to and from the probe and is defined mathematically by:

$$
E_{\mathrm{d}}=\frac{C_{\mathrm{out}}-C_{\mathrm{in}}}{C_{\mathrm{ext}}-C_{\mathrm{in}}}
$$

The reader is referred to UNIT 7.2 for more details on the application of this technique under steady-state and transient conditions (see Principles Underlying Microdialysis or Bungay et al., 1990, for more detailed mathematical description of $E_{\mathrm{d}}$ ).

Group comparison of $E_{\mathrm{d}}$ values can easily be made on data collected under steady-state and transient conditions. Typically, under steady-state conditions, all data necessary for calculation of the linear regression equation are collected in each subject. Therefore, each $E_{\mathrm{d}}$ is obtained for each subject and can be treated as any other dependent variable. Under transient conditions, the data necessary for calculation of the linear regression equation are collected from a group of subjects. In this case, $E_{\mathrm{d}}$ is obtained for each group and can be compared using standard regression statistics that test for parallelism of slopes. Group differences in $E_{\mathrm{d}}$ would suggest that probe efficacy varies by group and that differences in analyte dialysate levels reflect something more than a change in extracellular concentration (Justice, 1993).

The difference technique is easy to apply and analysis of in vivo $E_{\mathrm{d}}$ data is straightforward. Moreover, when group differences in $E_{\mathrm{d}}$ are observed, it is possible to use the $E_{\mathrm{d}}$ as a calibration tool to correct dialysate data to obtain extracellular concentrations and to test hypotheses concerning group differences in extracellular concentration.

Finally, theoretical consideration of the factors affecting $E_{\mathrm{d}}$ suggests that changes in $E_{\mathrm{d}}$ parallel changes in the rate of analyte clearance (see discussion of Principles Underlying Microdialysis). Therefore, changes in $E_{\mathrm{d}}$ can provide indirect measures of the rate of analyte clearance.

\section{Flow Rate Method}

The flow rate method was one of the first empirical methods designed to determine extracellular concentration by determining the relationship between perfusate flow rate, the active area of the membrane, and the mass transfer coefficient and then extrapolating to the case of zero flow rate (Jacobson et al., 1985). The dialysate concentration at zero flow rate is expected to be equal to the extracellular concentration of undisturbed tissue. The equation:

$$
C_{\text {out }} / C_{\mathrm{ext}}=1-\exp \left(-K_{0} A / F\right)
$$

is written to describe $E_{\mathrm{d}}$, where $C_{\text {out }}$ is the concentration in the dialysis probe, $C_{\mathrm{ext}}$ is the concentration of analyte in undisturbed tissue, $K_{0}$ is the mass transfer coefficient, $A$ is the active area of the microdialysis probe membrane, and $F$ is the perfusion flow rate. This equation can be related to the mathematical model of $E_{\mathrm{d}}$ described above (see Principles Underlying 
Microdialysis). Here $K_{0} A$ is equivalent to $1 /\left(R_{\mathrm{d}}+R_{\mathrm{m}}+R_{\mathrm{e}}\right)$, and the entire expression is equivalent to $E_{\mathrm{d}}$ (Bungay et al., 1990).

The above equation describes a nonlinear regression to a set of dialysate data collected at varying flow rates. The nonlinearity is not surprising given that the source of greatest resistance will vary by flow rate. The source of maximum resistance to transport of the analyte when $E_{\mathrm{d}}$ is low will lie in the external solution, while the source of maximum resistance to transport of the analyte when $E_{\mathrm{d}}$ is high will lie in the membrane. This is a limiting factor for the use of this technique since it does not yield a single best fit as in linear regression (Parsons and Justice, 1994). Furthermore, most of the data should be obtained at very low flow rates $(<1 \mathrm{mM} / \mathrm{min})$ to increase the accuracy of the regression analysis in its most dynamic range. Unfortunately, low flow rates require long collection periods to obtain appropriate sample volumes. Some attempts to overcome these limitations have been addressed; however, this technique has had limited application (Stahle et al., 1991; Menacherry et al., 1992).

\section{Internal Standard Method}

The internal standard method measures $E_{\mathrm{d}}$ by measuring the loss of an internal standard from the perfusate (Larsson, 1991; Scheller and Kolb, 1991). Extraction fraction is given as the relative loss of the standard (RL) as shown by:

$$
R L=E_{\mathrm{d}}=\frac{C_{\text {in }}-C_{\text {out }}}{C_{\text {in }}}
$$

where $C_{\mathrm{in}}$ is the starting concentration of the internal standard and $C_{\text {out }}$ is the dialysate concentration of the internal standard. The internal standard is usually a radiolabeled version of the analyte of interest. The assumption is that perfusion of the internal standard across the dialysis membrane is not limited regardless of the amount of unlabeled analyte present. This assumption has received support from in vitro studies in which increasing concentrations of the analyte of interest in the test solution did not change RL (Scheller and Kolb, 1991). With this method it is necessary to show that the labeled standard is diffusionally similar to the unlabeled analyte (e.g., has a similar diffusion coefficient through the membrane and similar clearance mechanisms in tissue), and one must avoid high concentrations that would tend to make the membrane the limiting site of diffusion in the overall diffusional path (Le Quellec et al., 1995; Lonnroth and Strindberg, 1995).

\section{In Vitro Recovery Method}

When the primary resistance of the membrane is greater than the resistance of the external medium, then no difference between in vitro recovery and in vivo recovery is expected. Circumstances in which this might occur are found in microdialysis protocols that use very slow flow rates and/or long dialysis fibers, or diffusionally resistant membranes (e.g., when high-molecular-weight substances are sampled or membranes with very small pore sizes are used). Unfortunately, use of a highly resistant membrane is typically not possible, because $E_{\mathrm{d}}$ becomes so low that the detectability of the analyte is compromised (Bungay et al., 1990). Slow perfusate flow rates yield nearly $100 \%$ recovery but require a relatively long collection period, or very small sample volume, which may compromise other aspects of the experiment (Menacherry et al., 1992). In vitro recovery methods may become more advantageous as more sensitive detection sampling and holding methods become available.

\section{FACTORS AFFECTING IN VIVO RECOVERY}

During microdialysis, analytes pass through a semipermeable membrane from the extracellular fluid (ECF) into a perfusate that is collected over a predetermined time and volume. Because the membrane is semipermeable only some solutes, namely, low-molecular-weight solutes, 
will be recovered. The concentration of analyte collected by this method will represent only a fraction of the ECF concentration.

The factors determining the amount of analyte recovered during microdialysis are described below. Consideration of these factors during the design phase of a microdialysis experiment will greatly enhance the success of that experiment (see Strategy for Determining Experimental Design) by assuring detectable levels of analyte in each dialysate sample. In addition, an understanding of these factors reveals the mechanisms that contribute to the stability of recovery during a microdialysis experiment. A major assumption underlying the application of conventional microdialysis methods is that analyte recovery is at steady state throughout the sampling period. Thus, consideration of the factors that contribute to changes in analyte recovery may facilitate the experimental design and interpretation of the results.

\section{Flow Rate}

Relative recovery of an analyte (concentration of analyte per sample) is inversely proportional to the perfusate flow rate (Johnson and Justice, 1983; Tossman et al., 1986; Wages et al., 1986; Alexander et al., 1988; Benveniste, 1989). Thus, as the flow rate decreases the concentration of analyte in each sample increases. Furthermore, at lower flow rates the net depletion of solutes around the probe decreases. For analytes with low extracellular concentration or low diffusivity, reducing the flow rate will increase the relative recovery and, therefore, increase the probability of obtaining a detectable concentration of analyte in each sample.

At extremely low flow rates $(<0.1 \mu \mathrm{l} / \mathrm{min})$ it is possible to reach near $100 \%$ recovery of an analyte, in which case the dialysate concentration of that analyte would equal the ECF analyte concentration (Van Wylen et al., 1986; Menacherry et al., 1992; Smith et al., 1992). The flow rate necessary to achieve $100 \%$ relative recovery depends on both the diffusional characteristics of the analyte under study as well as the membrane type and length. Smith et al. (1992), using a 4-mm regenerated cellulose membrane in rat striatum, perfused artificial cerebrospinal fluid (aCSF) at a rate of $0.057 \mu 1 /$ min and obtained dialysate concentrations of DA and DOPAC (3,4-dihdroxyphenylacetic acid) similar to the in vivo extracellular concentration of these analytes (as estimated by the difference method). Van Wylen et al. (1986) used $0.1 \mu \mathrm{l} / \mathrm{min}$ to obtain near $100 \%$ recovery of adenosine, validated in vitro, using a $4-\mathrm{mm}$ probe membrane in rat striatum. These flow rates do not typically yield sufficient time or volume resolution to be practical in most microdialysis experiments. Furthermore, for many analytes, low flow rates are not necessary to achieve detectable concentrations in dialysates. However, for situations in which long times and/or low volume sample handling are possible, slow flow rates offer the advantage of providing direct measurements of extracellular concentration.

The absolute recovery of an analyte (amount of analyte per sample) is proportional to the perfusate flow rate, up to flow rates of $2 \mu \mathrm{l} / \mathrm{min}$ (Wages et al., 1986; Benveniste, 1989). Thus, for analytical assays in which the total amount of analyte, rather than concentration, is measured (e.g., radioimmunoassay) it may be advantageous to use higher, rather than lower, flow rates (up to $2 \mu \mathrm{l} / \mathrm{min}$ ) to achieve a sufficient quantity of sample for detection. However, at these higher flow rates, probe efficiency is reduced (probe efficiency is equivalent to relative recovery), and the probe may be more sensitive to changes in the diffusional characteristics of the analyte in tissue.

\section{Microdialysis Probe Membrane Properties}

Recovery is proportional to the membrane surface area of the probe (Hamberger et al., 1983; Johnson and Justice, 1983; Sandberg and Lindstrom, 1983; Ungerstedt, 1984; Tossman et al., 1986; Kendrick, 1989, 1990), assuming no change in the homogeneous nature of the tissue 
surrounding the probe. More often than not, the length of the microdialysis probe is limited by the size of the structure under study.

Probe membrane material may also affect analyte recovery (Ungerstedt, 1984; Kendrick 1989, 1990; Hsiao et al., 1990; Mason and Romano, 1995). The membrane materials currently used in microdialysis probes are regenerated cellulose (Cuprophan from Gambro AB), polyacrylonitrile (PAN), and polycarbonate-ether (proprietary to CMA/Microdialysis). Kendrick $(1989,1990)$ determined the in vitro recovery for a large number of analytes using probes representative of each type of material and found a great degree of variation in recovery among probe types. These results could be accounted for by differences in the diffusional properties of the analyte in the membrane (see also Mason and Romano, 1995). In vivo, however, relative recovery may be more a function of the diffusional characteristics of the analyte in tissue than in the membrane (Bungay et al., 1990), and so similar differences in recovery among membrane types may not occur in vivo.

Hsiao et al. (1990) compared the in vitro and in vivo recovery of acetaminophen, DOPAC, hydroxyvalproic acid (HVA), and 5-hydroxyindoleacetic acid (5-HIAA) among the three membrane types and found large, significant differences in the in vitro relative recovery. In contrast, no consistent differences in recovery were found in vivo. The latter results suggest that membrane material may have little impact on in vivo recovery under conditions in which the maximum diffusional resistance resides in the tissue, as is typically true for low-molecularweight solutes. However, as molecular weight increases or if hindrance to analyte diffusion in the membrane increases (e.g., sticky compound; Kendrick, 1989, 1990) significant differences in probe efficiency (relative recovery) as a function of membrane material would be predicted, since the greatest source of diffusional resistance to the analyte would be found in the membrane (Bungay et al., 1990).

\section{Analyte Properties}

A large number of analytes have been collected by microdialysis (see Table 7.1.1). Reports of relative recovery for different analytes vary considerably. This is due, in part, to differences among laboratories in the microdialysis procedure used (i.e., flow rate, membrane length). However, substantial differences in recovery as a function of molecular weight and hydrophobicity can also be shown. By far, the most complete analysis of recovery by analyte type was performed by Kendrick (1989), who determined the in vitro relative recovery of more than 40 analytes under similar conditions $(2 \mu \mathrm{l} / \mathrm{min}$ flow rate using the same probe immersed in a solution maintained at $37^{\circ} \mathrm{C}$ ). By analyte class, relative recovery was highest for amino acids ( $33 \%$ to $40 \%$ ), followed by monoamines ( $22 \%$ to $30 \%$ ) and then neuropeptides (1.5\% to $24 \%)$.

Kendrick (1989) observed a strong negative linear relationship between molecular weight and the log percent recovery, suggesting that one explanation for the differences in relative recovery among analytes may be molecular weight. This is not surprising given the inverse relationship between molecular weight and the diffusion coefficient: as molecular weight increases the diffusion coefficient decreases. The lowest relative recoveries were observed for neuropeptides that had greater hydrophobic properties ("sticky"), suggesting that, for these analytes, hindrance may be a significant impediment to their collection by microdialysis. Dialysate levels obtained from sticky analytes also respond slowly to changes in the external concentration of the analyte (particularly decreases) and generally require considerably longer periods of equilibration to achieve a steady level of recovery (Kendrick, 1989; Thompson et al., 1995). (Note that recovery may be concentration dependent for sticky analytes, confounding the interpretation of experimental manipulations on dialysis data.) 


\section{Temperature}

Recovery is proportional to temperature. Temperature directly impacts on recovery by its effects on the diffusion coefficient; a $1 \%$ to $2 \%$ increase in the diffusion coefficient is observed for every degree Celsius increase in temperature (Bard and Faulkner, 1980). Significant differences in relative recovery between solutions maintained at $23^{\circ}$ and $37^{\circ} \mathrm{C}$ have been observed during in vitro assays for a number of different analytes (Wages et al., 1986; Alexander et al., 1988; Benveniste et al., 1989; Lindefors et al., 1989b; Parry et al., 1990). These studies demonstrate that analyte recovery evaluated at room temperature $\left(23^{\circ}\right.$ to $\left.25^{\circ} \mathrm{C}\right)$ underestimates in vivo analyte recovery. If the goal of an in vitro assay is to correspond as closely as possible to the in vivo condition, it is necessary to assess recovery at the expected in vivo temperature (typically $37^{\circ} \mathrm{C}$ ). The impact of temperature on relative recovery decreases as recovery approaches $100 \%$ (Alexander et al., 1988). Therefore, when microdialysis conditions favor near $100 \%$ recovery, it may not be necessary to adjust for in vitro versus in vivo differences in temperature.

\section{Tissue Factors}

Diffusion in tissue is typically slower than in an aqueous solution. This phenomenon is due, in great part, to the reduced fluid volume and increased diffusional path (or tortuosity) characteristic of tissue (Nicholson and Rice, 1986; Amberg and Lindefors, 1989; Lindefors et al., 1989b; Benveniste and Huttemeier, 1990). Moreover, diffusion in tissue may be slowed further by analyte binding to cell surface proteins along the diffusional path (Rice et al., 1985). This means in vivo recovery of an analyte should be less than in vitro recovery of that analyte in a stirred solution held at $37^{\circ} \mathrm{C}$. However, these factors alone do not adequately describe the difference between in vitro and in vivo estimates of relative recovery, perhaps because, in tissue, diffusion of an analyte is also influenced by the rate of analyte clearance (Bungay et al., 1990; Morrison et al., 1991; Dykstra et al., 1992). As the rate of analyte clearance increases, resistance to diffusion decreases. Diffusivity in tissue, then, is somewhat greater for substances, like neurotransmitters, that are rapidly cleared from the extracellular space.

Of course, the extent to which relative recovery, or probe efficiency, during in vivo microdialysis is affected by tissue factors depends on in which medium (tissue, membrane, or perfusate) the greatest resistance to diffusion occurs. When relative recovery is low, most lowmolecular-weight hydrophilic substances will meet the greatest diffusional resistance in tissue. In these cases, changes in the physiological characteristics of tissue (i.e., fluid volume, tortuosity, hindrance, and rate of analyte clearance) that affect diffusional resistance will modify probe efficiency in a given microdialysis experiment. The problem is twofold. First, decreases in recovery in vivo as a result of reduced fluid volume, increased tortuosity, and/or increased hindrance in tissue may reduce the dialysate levels of the analyte below the sensitivity of the analytical detection device. Second, experimental treatments (e.g., lesions, drug treatments) or procedures (e.g., implantation of the microdialysis probe) that affect these physiological characteristics of the tissue may lead to changes in probe efficiency. Group differences in probe efficiency and changes in probe efficiency over the course of the microdialysis sampling period would tend to complicate or confound the interpretation of differences in dialysate concentration of the analyte.

\section{PERFUSATE COMPOSITION}

The perfusate is typically composed of low-molecular-weight substances, mainly ions, in concentrations similar to those found in the extracellular fluid. Perfusate composition is important because perfusate components diffuse into the tissue in the same way that the analyte of interest diffuses into the microdialysis probe. Furthermore, any solute in the extracellular fluid that is small enough to pass through the dialysis membrane, and is in a lower concentration 
than that in the perfusate, will diffuse into the perfusate and be depleted from the extracellular fluid surrounding the probe.

Ideally, then, the perfusate should contain the exact concentration of all solutes that diffuse through the probe membrane and are found in the extracellular fluid, except of course that solute meant to be sampled. In practice, however, this is neither possible nor pragmatic. Instead, microdialysis perfusates are most often made with the ionic composition and $\mathrm{pH}$ of plasma (Ringer's solutions) or artificial cerebrospinal fluid (aCSF or mock CSF).

Maintaining proper ionic composition is critical in the evaluation of neurochemical events. The ionic milieu of neuronal extracellular fluid differs from plasma in both concentration and lability (Bradbury, 1979; Wood and Wood, 1980). Numerous reports have shown that small differences in perfusate $\mathrm{Ca}^{2+}$ concentration produce marked effects on basal neurotransmitter levels (Westerink et al., 1988; Moghaddam and Bunney, 1989; Osborne et al., 1991). Moreover, changing the concentration of $\mathrm{K}^{+}$in the perfusate is a standard technique used to induce neuronal release of many neurotransmitters (Spanagel et al., 1990; Parsons and Justice, 1992; Thompson et al., 1995). Interestingly, Obrenovitch et al. (1995) showed that the concentration of ions in aCSF may act to "buffer" experimentally induced changes in the ionic composition of neural tissue (i.e., spreading depression). In this case, increasing the $\mathrm{K}^{+}$ concentration in the perfusate was necessary to permit the development of spreading depression in neural tissue. These effects are not surprising given the importance of ion concentration and distribution in the regulation of neuronal activity and emphasize the importance of maintaining appropriate ionic concentrations.

Information regarding the issue of solute depletion around the probe is limited. The magnitude of solute depletion is directly related to the flow rate, such that as flow rate increases solute depletion increases. Sam and Justice (1996) used this relationship to directly test the effect of increasing the solute depletion (by increasing the flow rate) on basal extracellular DA concentration in the rat striatum. They found that changes in the amount of total solute depletion around the microdialysis probe did not, in fact, affect basal extracellular DA concentrations. More research is necessary to determine how well this finding generalizes to other neurochemicals. It is known that the extracellular concentrations of many analytes are regulated by other neurochemicals in the interstitial space. Thus, during microdialysis, there could be depletion of a substance(s) that in turn regulates the analyte under study.

Finally, it should be noted that the perfusate can be used to deliver agents into tissue, as well as to provide preservative agents (e.g., antioxidants) or other substances that aid in the recovery of the analyte once it has diffused into the perfusate (e.g., bovine serum albumin or antibodies). Microdialysis probes can be used to locally administer either a continuous or pulse infusion of drugs. One advantage of this delivery method over microinjections is that the drug is delivered by measurable parameters of diffusion (and possibly ultrafiltration). As a result, precise calculations of the "dose" and area affected can be determined (Bungay et al., 1990).

Preservatives are usually not diffusable through the membrane, thus eliminating the possibility of adding an undesirable compound to the tissue. Bovine serum albumin, which is too large to pass through most microdialysis membranes, has been used to reduce the adsorption of sticky analytes to the probe tubing and collection vials (Kendrick, 1989). Antibodies have also been used for similar purposes (Lambert et al., 1994). Some consideration of the impact of adding these substances on the subsequent analyte detection is often necessary.

Ascorbic acid is frequently included in perfusates when monoamines, particularly DA, are being collected to reduce analyte degradation after collection. Ascorbic acid readily diffuses through most microdialysis membranes and is known to impact on the neurochemical milieu, but it is also found endogenously. Its perfusate concentration should be limited to no more than 
that found in tissue ( $\sim 0.2 \mathrm{mM}$ in interstitial fluid). Ascorbate is also electroactive and typically has a short retention time. Because of the high concentration of ascorbate, however, samples containing ascorbate will typically have a long solvent front. Therefore, standards containing known concentrations of DA with ascorbate, or any protective agent, should be tested before adopting it into the experimental protocol.

\section{STRATEGY FOR DETERMINING EXPERIMENTAL DESIGN}

To summarize what has been described in this unit, microdialysis is a collection method based on the principle of simple diffusion. A membrane that is permeable to water and small solutes separates two fluid compartments. Molecules migrate across the semipermeable membrane along their concentration gradient. Thus, molecules found in high concentrations within a tissue compartment will diffuse into the probe, where they can be collected for subsequent quantification. A significant advantage of the microdialysis method is that a variety of analytical techniques (e.g., electrochemical detection, radioimmunoassay, and mass spectrometry; also see UNIT 7.4) can be used for the separation and quantification of the analyte of interest.

The challenge in designing and implementing a microdialysis experiment is to collect a sample with both sufficient volume and concentration of analyte to permit separation and detection by the analytical technique employed, while satisfying the experimental design specified by the research question. Therefore, the first step in designing a dialysis experiment is to obtain information regarding the analytical sensitivity and minimum volume of dialysate necessary to isolate and quantify the analyte(s) of interest. Familiarity with the physicochemical properties of the analyte of interest (e.g., molecular weight, lipophilicity) and its distribution, concentration, and clearance from the tissue of interest will greatly facilitate subsequent experimental design.

The volume of the collected dialysis sample is determined by the flow rate $(\mu 1 / \mathrm{min})$ of the fluid that is perfused through the probe (perfusate) and the collection period ( $\mathrm{min})$. The concentration of analyte in the collected sample is dependent on the relative recovery of the analyte by the microdialysis probe (also referred to as probe efficiency) and the analyte concentration in tissue. An estimate of tissue concentration can generally be obtained from the literature. Relative recovery is dependent on a number of factors that affect diffusion of the analyte from the tissue to the perfusate, including perfusate composition, membrane composition, active area (or length) of the membrane, flow rate, temperature, and, in many cases, diffusional characteristics of the analyte(s) in tissue. Small changes in these factors may produce significant changes in relative recovery of the analyte(s). In addition, other factors such as the material and surface area of the outflow tubing employed, tubing length, and method of sample storage may diminish the actual concentration of an analyte in the sample. For example, some analytes are particularly prone to adsorption to materials such as the surface of the outflow tubing or the inner surface of the collection vial. Others may have low thermal stability (e.g., monoamines that are oxidized) and degrade quickly following collection. Fortunately, many of these problems have been identified in the literature or can be resolved using in vitro assays.

The following strategy is recommended for investigators first setting up microdialysis, or for those establishing procedures for the collection of substances not already described in the literature.

1. Determine the sensitivity of the analytical equipment and the minimum sample volume required for the handling of physiologically relevant levels of analyte.

2. Determine if any loss of the analyte might occur following its diffusion into the microdialysis probe. This can be assessed by perfusing a known concentration of the 
analyte of interest through the inflow/outflow tubing into a collection vial. The concentration of analyte in the collection vial should be the same as the starting concentration. A physiologically relevant concentration(s) of the analyte of interest should be used, and any additional equipment, such as a liquid switch, that the analyte might contact should be tested in this way. If significant loss of analyte is found, then the source of the loss can be identified by systematically testing each component of the dialysis setup. Loss of analyte to the tubing, collection vial, or any other piece of equipment through the which the perfusate flows is often the result of surface adsorption. However, degradation of the sample by enzymes (from a bacterial source) or physicochemical interactions (e.g., oxidation) with metal or tubing may also contribute to sample loss.

3. Evaluate the sample storage method. Two issues should be considered. First, some analytes will degrade rapidly at room temperature (e.g., monoamines). Therefore, optimal collection and storage conditions must be determined. Frequently, reducing the temperature of the sample once it is collected or including a protective agent in the collection vial or perfusate will increase analyte stability. For example, the addition of ascorbic acid to the perfusate or perchloric acid to the collection vial will protect catecholamines from oxidative degradation. Second, because microdialysis samples tend to be very small (in the microliter range), evaporation of the sample may occur over long collection periods. In this case, it would be advisable to seal the collection vials during sample collection.

4. Consider the length and diameter of the inflow/outflow tubing. The combination of long, narrow tubing and higher flow rates may produce considerable back pressure in the probe, resulting in ultrafiltration ("sweating") of the perfusate. The net impact on sample collection will be a reduction in relative recovery. In addition, it is important to know the "dead volume" for each dialysis setup, as this will affect the calculated time course of a given neurochemical response. For example, if the capacity of the outflow tubing is $10 \mu \mathrm{l}$ and the perfusion rate is $2.0 \mu \mathrm{l} / \mathrm{min}$, there will be a 5 -min lag in measuring the response to a given manipulation.

5. Choose a probe membrane. The molecular weight cutoff should be considerably larger than the analyte of interest yet small enough to maintain the semipermeable nature of the membrane. Several types of membranes are used commercially, and at least one report has shown that some membrane materials may be better suited for the collection of analytes that prove to be sticky, e.g., hydrophobic neuropeptides; see Kendrick (1990) and UNIT 7.2.

6. Determine the maximum length of active membrane accessible to the tissue under study. The goal here is to increase the surface area through which dialysis occurs. The surface area of a microdialysis probe is increased by increasing the length, and not the diameter, of the probe. In tissue, the maximum length of the probe is generally dictated by the size of the region in which the probe will be implanted. When probe length is not limited by tissue size, the length should be great enough to produce maximum or near maximum recovery. The effect of probe length on analyte recovery can be easily determined in vitro.

7. Choose a perfusate that is compatible with the organ system and analyte being measured. As a rule, perfusion fluids should be isoosmotic. Remember that diffusion during microdialysis is bidirectional, so that low-molecular-weight solutes in the perfusate will diffuse out of the probe and into tissue.

8. Determine the longest collection period that will still permit hypothesis testing. Typically, the longer the collection period the slower is the flow rate necessary to yield a sufficient volume for analytical detection. 
9. Choose a flow rate that will yield sufficient volume for the desired collection period. Slower flow rates will increase the relative recovery of the analyte of interest.

10. Use an in vitro assay to determine if the flow rate and collection period selected yield a sample with a detectable concentration of analyte (use an estimate of actual extracellular tissue concentration).

11. Consider an in vivo pilot procedure to assure adequate sample recovery before investing in a larger experiment.

\section{LITERATURE CITED}

Abercrombie ED, Zigmond MJ. Partial injury to central noradrenergic neurons: Reduction of tissue norepinephrine content is greater than reduction of extracellular norepinephrine measured by microdialysis. J. Neurosci 1989;9:4062-4067. [PubMed: 2511282]

Alexander GM, Grothusen JR, Schwartzman RJ. Flow dependent changes in the effective surface area of microdialysis probes. Life Sci 1988;42:595-601. [PubMed: 2899830]

Amberg G, Lindefors N. Intracerebral microdialysis: II. Mathematical studies of diffusion kinetics. J. Pharmacol. Methods 1989;22:157-183. [PubMed: 2586112]

Bard, AG.; Faulkner, LR. Electrical Methods. New York: John Wiley \& Sons; 1980. p. 153

Benveniste H. Brain microdialysis. J. Neurochem 1989;52:1667-1679. [PubMed: 2656913]

Benveniste H, Huttemeier PC. Microdialysis: Theory and application. Prog. Neurobiol 1990;35:195-215. [PubMed: 2236577]

Benveniste H, Hansen AJ, Ottosen NS. Determination of brain interstitial concentrations by microdialysis. J. Neurochem 1989;52:1741-1750. [PubMed: 2723633]

Bito L, Davson H, Levin E, Murray M, Snider N. The concentration of free amino acids and other electrolytes in cerebrospinal fluid: In vivo dialysis of brain and blood plasma of the dog. J. Neurochem 1966;13:1057-1067. [PubMed: 5924657]

Blomquist L, Dizdar N, Karlsson M, Kagedal B, Ossowicki H, Pettersson A, Smeds S. Microdialysis of 5-S-cysteinyldopa from interstitial fluid in cutaneous human melanoma transplanted to athymic mice. Melanoma Res 1991;1:23-32. [PubMed: 1822767]

Bourdelais AJ, Kalivas PW. Modulation of extracellular gamma-aminobutyric acid in the ventral pallidum using in vivo microdialysis. J. Neurochem 1992;58:2311-2320. [PubMed: 1315380]

Bradbury, MWB. The Concept of a Blood-Brain Barrier. New York: John Wiley \& Sons; 1979.

Bruhn T, Christensen T, Diemer NH. Microdialysis as a tool for in vivo investigation of glutamate transport capacity in rat brain. J. Neurosci. Methods 1995;59:169-174. [PubMed: 8531483]

Brust P, Diemer NH. Blood-brain transfer of 1-phenylalanine declines after peripheral but not central nervous administration of vasopressin. J. Neurochem 1990;55:2098-2104. [PubMed: 2230811]

Bungay PM, Gonzales RA. Pressure enhanced delivery of solutes by microdialysis. Soc. Neurosci. Abstr 1996;22(Part 3):2076.

Bungay PM, Morrison PF, Dedrick RL. Steady-state theory for quantitative microdialysis of solutes and water in vivo and in vitro. Life Sci 1990;46:105-119. [PubMed: 2299972]

Callaghhan DH, Yergey JA, Rousseau P, Masson P. Respiratory tract eicosanoid measurement using microdialysis sampling and GC/MS detection. Pulm. Pharmacol 1994;7:35-41. [PubMed: 8003850]

Chen Y, Graham DI, Stone TW. Release of endogenous adenosine and its metabolites by the activation of NMDA receptors in the rat hippocampus in vivo. Br. J. Pharmacol 1992;106:632-638. [PubMed: 1354544]

Chiueh CC, Krishna G, Tulsi P, Obata T, Lang K, Huang SJ, Murphy DL. Intracranial microdialysis of salicylic acid to detect hydroxyl radical generation through dopamine auto-oxidation in the caudate nucleus: Effects of MPP ${ }^{+}$Free Radic. Biol. Med 1992;13:581-583. [PubMed: 1334031]

Consolo S, Wu CF, Fusi R. D-1 receptor linked mechanism modulates cholinergic neurotransmission in rat striatum. J. Pharmacol. Exp. Ther 1987;242:300-305. [PubMed: 2886638] 
Cosford RJ, Parsons LH, Justice JB Jr. Effect of tetrodotoxin and potassium infusion on microdialysis extraction fraction and extracellular dopamine in the nucleus accumbens. Neurosci. Lett 1994;178:175-178. [PubMed: 7824191]

Cosford RJ, Vinson AP, Kukoyi S, Justice JB Jr. Quantitative microdialysis of serotonin and norepinephrine: Pharmacological influences on in vivo extraction fraction. J. Neurosci. Methods 1996;68:39-47. [PubMed: 8884611]

Damsma G, Westerink BHC, Imperato A, Rollema H, de Vries JB, Horn AS. Automated brain dialysis of acetylcholine in freely moving rats: Detection of basal acetylcholine. Life Sci 1987;41:873-876. [PubMed: 3613848]

de Boer J, Plijter-Groendijk H, Korf J. Continuous monitoring of glucose with a transcutaneous microdialysis probe [letter]. Lancet 1992;340:547-548. [PubMed: 1354295]

Deleu D, Sarre S, Ebinger G, Michotte Y. Simultaneous monitoring of levodopa, dopamine, and their metabolites in skeletal muscle and subcutaneous tissue in different pharmacological conditions using microdialysis. J. Pharm. Biomed. Anal 1993;11:557-585. [PubMed: 8399529]

Delgado JMR, DeFeudis FV, Roth RH, Ryugo DK, Mitruka BK. Dialytrode for long term intracerebral perfusion in awake monkeys. Arch. Int. Pharmacodyn 1972;198:9-21. [PubMed: 4626478]

Dev BR, Mason PA, Freed CR. Drug-induced changes in blood pressure lead to changes in extracellular concentrations of epinephrine, dihydroxyphenylacetic acid, and 5-hydroxyindoleacetic acid in the rostral ventrolateral medulla of the rat. J. Neurochem 1992;58:1368-1394.

Dietze S, Kushinsky K. Determination of extracellular glutamate after local $\mathrm{K}^{+}$stimulation in the striatum of non-anaesthetized rats after treatment with dopaminergic drugs: Studies using microdialysis. J. Neural Transm. Gen. Sect 1992;90:1-11. [PubMed: 1361342]

Dizdar N, Kagedal B, Smeds S, Arstrand K. A high sensitivity fluorometric high-performance liquid chromatographic method for determination of glutathione and other thiols in cultured melanoma cells, microdialysis samples from melanoma tissue, and blood plasma. Melanoma Res 1991;1:3342. [PubMed: 1822768]

During MJ, Bean AJ, Roth RH. Effects of CNS stimulants on the in vivo release of the colocalized transmitters, dopamine and neurotensin, from rat prefrontal cortex. Neurosci. Lett 1992;140:129133. [PubMed: 1407692]

Dykstra KH, Hsiao JK, Morrison PF, Bungay PM, Mefford IN, Scully MM, Dedrick RL. Quantitative examination of tissue concentration profiles associated with microdialysis. J. Neurochem 1992;58:931-940. [PubMed: 1738000]

Einspanier R, Miyamoto A, Schams D, Muller M, Brem G. Tissue concentration, mRNA expression and stimulation of IGF-I in luteal tissue during the oestrous cycle and pregnancy of cows. J. Reprod. Fertil 1990;90:439-445. [PubMed: 2250243]

Ferraro TN, Weyers P, Carrozza DP, Vogel WH. Continuous monitoring of brain ethanol levels by intracerebral microdialysis. Alcohol 1990;7:129-132. [PubMed: 2328086]

Friedman, MH. Principles and Models of Biological Transport. New York and Heidelberg: SpringerVerlag; 1986. Free diffusion; p. 22-41.

Fukui H, Yamamoto M, Ando T, Sasaki S, Sato S. Increase in serotonin levels in the dog ileum and blood by cisplatin as measured by microdialysis. Neuropharmacology 1993;32:959-968. [PubMed: 8295718]

Glass JD, Randolph WW, Ferriera SA, Rea MA, Hauser UE, Blank JL, De Vries MJ. Diurnal variation in 5-hydroxyindole-acetic acid output in the suprachiasmatic region of the Siberian hamster assessed by in vivo microdialysis: Evidence for nocturnal activation of serotonin release. Neuroendocrinology 1992;56:582-590. [PubMed: 1282219]

Glick SD, Dong N, Keller RW Jr, Carlson JN. Estimating extracellular concentration of dopamine and 3,4-dihydroxyphenylacetic acid in nucleus accumbens and striatum using microdialysis: Relationship between in vitro and in vivo recoveries. J. Neurochem 1994;62:2017-2021. [PubMed: 8158149]

Golden PL, Brouwer KR, Pollack GM. Assessment of valproic acid serum-cerebrospinal fluid transport by microdialysis. Pharmacol. Res 1993;10:1765-1771.

Guadalupe T, Gonzalez-Mora JL, Fumero B, Mas M. Voltammetric monitoring of brain extracellular levels of serotonin, 5-hydroxyindoleacetic acid and uric acid as assessed by simultaneous microdialysis. J. Neurosci. Methods 1992;45:159-164. [PubMed: 1284165] 
Hagberg H, Andersson P, Lacarewicz J, Jacobson I, Butcher S, Sandberg M. Extracellular adenosine, inosine, hypoxanthine, and xanthine in relation to tissue nucleotides and purines in rat striatum during transient ischemia. J. Neurochem 1987;49:227-231. [PubMed: 3585332]

Hallstrom A, Carlsson A, Hillered L, Ungerstedt U. Simultaneous determination of lactate, pyruvate, and ascorbate in microdialysis samples from the rat brain, blood, fat, and muscle using high-performance liquid chromatography. J. Pharmacol. Methods 1989;22:113-124. [PubMed: 2811388]

Hamberger, A.; Berthold, C-H.; Karlsson, B.; Lehmann, A.; Nystrom, B. Extracellular GABA, glutamate, and glutamine in vivo perfusion dialysis of the rabbit hippocampus. In: Herz, L.; Krammer, E.; McGee, EG.; Schousboe, A., editors. Neurology and Neurobiology, Vol. 7, Glutamine, Glutamate and GABA in the Central Nervous System. New York: Wiley-Liss; 1983. p. 473-492.

Hasegawa M, Ebihara S. Circadian rhythms of pineal melatonin release in the pigeon measured by in vivo microdialysis. Neurosci. Lett 1992;148:89-92. [PubMed: 1300510]

Hashizume T, Nitta Y, Kasuya K, Kanematsu S. Microdialysis of intracerebral somatostatin in the goat. Domestic Anim. Endocr 1995;12:363-370.

Hsiao JK, Ball BA, Morrison PF, Mefford IN, Bungay P. Effects of different semipermeable membranes on in vitro and in vivo performance of microdialysis probes. J. Neurochem 1990;54:1449-1452. [PubMed: 1690270]

Huang Y, Zielke CL, Tidon JT, Zielke HR. Monitoring in vivo oxidation of ${ }^{14} \mathrm{C}$-labeled substrates to ${ }^{14} \mathrm{CO}_{2}$ by brain microdialysis. Dev. Neurosci 1993;15:233-239. [PubMed: 7805575]

Hylland P, Nilsson GE, Johansson D. Anoxic brain failure in an ectothermic vertebrate: Release of amino acids and $\mathrm{K}^{+}$in rainbow trout thalamus. Am. J. Physiol 1995;269:R1077-R1084. [PubMed: 7503294]

Imperato A, Di Chiara G. Trans-striatal dialysis coupled to reverse-phase high performance liquid chromatography with electrochemical detection: A new method for study of the in vivo release of endogenous dopamine and metabolites. J. Pharmacol. Exp. Ther 1984;4:966-977.

Ingvast-Larsson C, Appelgren LE, Nyman G. Microdialysis of theophylline in the rat and horse. Acta Vet. Scand. Suppl 1991;87:330-332.

Itoh Y, Oishi R, Nishibori M, Saeki K. In vivo measurement of noradrenaline and 3',4dihydroxyphenylethyleneglycol in the rat hypothalamus by microdialysis: Effects of various drugs affecting noradrenaline metabolism. J. Pharmacol. Exp. Ther 1990;255:1090-1097. [PubMed: 2262894]

Jacobson I, Sandberg M, Hamberger A. Mass transfer in brain dialysis devices-new method for the estimation of extracellular amino acids concentration. J. Neurosci. Methods 1985;15:263-268. [PubMed: 4094481]

Johnson RD, Justice JB. Model studies for brain dialysis. Brain Res. Bull 1983;10:567-571. [PubMed: 6860982]

Jonsson P, Borgstrom A, Ohlsson K. Measurements of exocrine proteins in the pig pancreas using microdialysis. Gastroenterol. Jpn 1992;27:529-535. [PubMed: 1526434]

Justice JB Jr. Quantitative microdialysis of neurotransmitters. J. Neurosci. Methods 1993;48:263-276. [PubMed: 8105154]

Kendrick KM. Use of microdialysis in neuroendocrinology. Methods Enzymol 1989;168:182-205. [PubMed: 2566890]

Kendrick KM. Microdialysis measurement of in vivo neuropeptide release. J. Neurosci. Methods 1990;34:35-46. [PubMed: 2259245]

Kendrick KM, Keverne EB, Chapman C, Baldwin BA. Microdialysis measurement of oxytocin, aspartate, gamma-aminobutyric acid and glutamate release from olfactory bulb of the sheep during vaginocervical stimulation. Brain Res 1988;442:171-174. [PubMed: 2896051]

Kendrick KM, De la Riva C, Hinton M, Baldwin BA. Microdialysis measurements of monoamine and amino acid release from the medial preoptic region of the sheep in response to heat exposure. Brain Res. Bull 1989;22:541-544. [PubMed: 2713726]

Khan-Dawood FS, Gargiulo AR, Dawood MY. Baboon corpus lutem: Autonomous pulsatile progesterone secretion and evidence for an intraluteal oscillator demonstrated by in vitro microretrodialysis. J. Clin. Endocrinol. Metab 1994;79:1790-1796. [PubMed: 7989486] 
Kubota M, Atobe M, Hirano M, Nakagawara M, Kariya T. Hypothalamic MHPG measured by microdialysis in rats with PNMT inhibitors. Jpn. J. Psychiatry Neurol 1993;47:428. [PubMed: 8271624]

Kuzmin AI, Selivanov VN, Sysoev AB, Medvedev OS. Study of catecholamine secretion by the rat adrenal glands using microdialysis in vivo. Fiziol. Zh 1990;36:14-20.

Kuzmin AI, Tskitishvili OV, Serebryakova LI, Saprygina TV, Kapelko VI, Medvedev OS. Cardiac microdialysis measurement of extracellular adenine nucleotide breakdown products during regional ischemia and reprofusion in canine heart: Protective effect of propranolol against reprofusion injury. J. Cardiovasc. Pharmacol 1992;20:961-968. [PubMed: 1282600]

Lahtinen H, Brankack J, Koivisto E, Riekkinen PJ. Somatostatin release in rat neocortex during gammahydroxybutyrate-provoked seizures: Microdialysis combined with EEG recording. Brain Res. Bull 1992;29:837-841. [PubMed: 1361875]

Lambert PD, Wilding JP, Turton MD, Ghatel MA, Bloom SR. Effects of food deprivation and streptozotocin-induced diabetes on hypothalamic neuropeptide $\mathrm{Y}$ release as measured by a radioimmunoassay-linked microdialysis procedure. Brain Res 1994;656:135-140. [PubMed: 7804826]

Larsson CI. The use of an "internal standard" for control of the recovery in microdialysis. Life Sci 1991;49:PL73-PL78. [PubMed: 1886451]

Le Quellec A, Dupin S, Genissel P, Saivin S, Marchand B, Houin G. Microdialysis probes calibration: Gradient and tissue dependent changes in no net flux and reverse dialysis methods. J. Pharmacol. Exp. Ther 1995;33:11-16.

Lincoln GA. Administration of melatonin into the mediobasal hypothalamus as a continuous or intermittent signal affects the secretion of follicle stimulating hormone and prolactin in ram. J. Pineal Res 1992;12:135-144. [PubMed: 1507056]

Lindefors N, Brodin E, Ungerstedt U. Amphetamine facilitates the in vivo release of neurokinin A in the nucleus accumbens of the rat. Eur. J. Pharmacol 1989a;160:417-420. [PubMed: 2540996]

Lindefors N, Amberg G, Ungerstedt U. Intracerebral microdialysis: I. Experimental studies of diffusion kinetics. J. Pharmacol. Methods 1989b;22:141-156. [PubMed: 2586111]

Linderoth B, Gazel-Gazaliuss B, Franck J, Brodin E. Dorsal column stimulation induces release of serotonin and substance P in the cat dorsal horn. Neurosurgery 1992;31:289-296. [PubMed: 1381066]

Ljungdahl-Stahle E, Guzeda E, Bottiger D, Wahren B, Oberg B, Stahle L. Penetration of zidovudine and 3'-fluoro-3'-deoxythymidine into the brain, muscle tissue and veins in cynomolgus monkeys: Relation to antiviral action. Antimicrob. Agents Chemother 1992;36:2418-2422. [PubMed: 1489185]

Lonnroth P, Strindberg L. Validation of the "internal reference technique" for calibrating microdialysis catheters in situ. Acta Physiol. Scand 1995;153:375-380. [PubMed: 7618484]

Lonnroth P, Jansson PA, Smith U. A microdialysis method allowing characterization of intercellular water space in humans. Am. J. Physiol 1987;253:E228-E231. [PubMed: 3618773]

Lonnroth P, Jansson PA, Fredholm BB, Smith U. Microdialysis of intercellular adenosine concentration in subcutaneous tissue in humans. Am J. Physiol 1989;256:E250-E255. [PubMed: 2645786]

Lonnroth P, Carlsten J, Johnson L, Smith U. Measurements by microdialysis of free tissue concentrations of propranolol. J. Chromatogr 1991;568:419-425. [PubMed: 1783646]

Louzada-Junior P, Dias JJ, Santos WF, Lachat JJ, Bradford HF, Coutinho-Netto J. Glutamate release in experimental ischaemia of the retina: An approach using microdialysis. J. Neurochem 1992;59:358363. [PubMed: 1351929]

Maidment NT, Brumbaugh DR, Rudolph VD, Erdelyi E, Evans CJ. Microdialysis of extracellular endogenous opioid peptides from rat brain in vivo. Neuroscience 1989;33:549-557. [PubMed: 2636708]

Mason PA, Romano WF. Recovery characteristics of a rigid, nonmetallic microdialysis probe for use in an electromagnetic field. Bioelectromagnetics 1995;16:113-118. [PubMed: 7612026]

Matsuyama K, Nakashima M, Nakaboh Y, Ichikawa M, Yano T, Satoh S. Application of in vivo microdialysis to transdermal absorption of methotrexate in rats. Pharmacol. Res 1994;11:684-686. 
Menacherry S, Hubert W, Justice JB Jr. In vivo calibration of microdialysis probes of exogenous compounds. Anal. Chem 1992;64:577-583. [PubMed: 1580357]

Miyamoto A, Schams D. Oxytocin stimulates progesterone release from microdialyzed bovine corpus luteum in vitro. Biol. Reprod 1991;44:1163-1170. [PubMed: 1873390]

Moghaddam B, Bunney BS. Ionic composition of microdialysis perfusing solution alters the pharmacological responsiveness and basal outflow of striatal dopamine. J. Neurochem 1989;53:652654. [PubMed: 2568406]

Morrison, PF.; Bungay, PM.; Hsiao, JK.; Mefford, IN.; Dykstra, KH.; Dedrick, RL. Quantitative microdialysis. In: Robinson, TE.; Justice, JB., Jr, editors. Microdialysis in the Neurosciences. New York: Elsevier Science Publishing; 1991. p. 47-80.

Nicholson C, Rice ME. The migration of substances in the neuronal microenvironment. Ann. N.Y. Acad. Sci 1986;481:55-71. [PubMed: 3468865]

Nielsen EO, Aarslew-Jensen M, Diemer NH, Krogsgaard-Larsen P, Schousboe A. Baclofen-induced, calcium-dependent stimulation of in vivo release of $\mathrm{d}-\left[{ }^{3} \mathrm{H}\right]$ aspartate from rat hippocampus monitored by intracerebral microdialysis. Neurochem. Res 1989;14:321-326. [PubMed: 2761667]

Nomoto M, Irifune M, Fukuzaki K, Fukuda T. Effects of bifemelane on parkinsonism induced by 1methyl-4-phenyl-1,2,3,6-tetrahydropyridine (MPTP) in the common marmoset. Neurosci. Lett 1994;178:95-98. [PubMed: 7816348]

Nordenvall M, Ulmsten U, Ungerstedt U. Influence of progesterone on the sodium and potassium concentrations of the rat uterine fluid investigated by microdialysis. Gynecol. Obstet. Invest 1989;28:73-77. [PubMed: 2792917]

Obrenovitch TP, Zikha E, Urenjak J. Intracerebral microdialysis: Electrophysiological evidence of a critical pitfall. J. Neurochem 1995;64:1884-1887. [PubMed: 7891118]

Okuda C, Sawa T, Harada M, Murakami T, Matsuda T, Tanaka Y. Lactate in rat skeletal muscle after hemorrhage measured by microdialysis probe calibrated in situ. Am. J. Physiol 1992a;263:E1035E1039. [PubMed: 1476174]

Okuda C, Sawa T, Harada M, Murakami T, Tanaka Y. Continuous measurement of lactate concentration in skeletal muscle and liver interstitium using a microdialysis method after acute hemorrhage in anesthetized rats. Circ. Shock 1992b;37:230-235. [PubMed: 1423914]

Osborne PG, O'Connor WT, Ungerstedt U. Effect of varying the ionic concentration of a microdialysis perfusate on basal striatal dopamine levels in awake rats. J. Neurochem 1991;56:452-456. [PubMed: 1988549]

Ota M, Crofton JT, Festavan G, Share L. Central carbachol stimulates vasopressin release into interstitial fluid adjacent to the paraventricular nucleus. Brain Res 1990;592:249-254. [PubMed: 1450914]

Parry TJ, Carter TL, McElligott JG. Physical and chemical considerations in the in vitro calibration of microdialysis probes for biogenic amine neurotransmitters and metabolites. J. Neurosci. Methods 1990;32:175-183. [PubMed: 1974665]

Parsons LH, Justice JB Jr. Extracellular concentration and in vivo recovery of dopamine in the nucleus accumbens using microdialysis. J. Neurochem 1992;58:212-218. [PubMed: 1727431]

Parsons LH, Justice JB Jr. Quantitative approaches to in vivo brain microdialysis. Crit. Rev. Neurobiol 1994;8:189-220. [PubMed: 7923396]

Petersen LJ, Skov PS, Bindslev-Jensen C, Sondergaard J. Histamine release in immediate-type hypersensitivity reactions in intact human skin measured by microdialysis: A preliminary study. Allergy 1992a;47:635-637. [PubMed: 1283659]

Petersen LJ, Kristensen JK, Bulow J. Microdialysis of the interstitial water space in human skin in vivo: Quantitative measurement of cutaneous glucose concentrations. J. Invest. Dermatol 1992b; 99:357-360. [PubMed: 1512473]

Rice ME, Gerhardt GA, Hierl PM, Nagy G, Adams RN. Diffusion coefficients of neurotransmitters and their metabolites in brain extracellular fluid space. Neuroscience 1985;15:891-902. [PubMed: 2866468]

Rollema H, Alexander GM, Grothusen JR, Matos FF, Castagnoli N. Comparison of the effects of intracerebrally administered $\mathrm{MPP}^{+}$(1-methyl-4-phenylpyridinium) in three species: Microdialysis of dopamine and metabolites in mouse, rat and monkey striatum. Neurosci. Lett 1989;106:275-281. [PubMed: 2601882] 
Russi P, Alesiani M, Lombardi G, Davolio G, Pellicciari R. Nicotinylalanine increases the formation of kynurenic acid in the brain and antagonizes convulsions. J. Neurochem 1992;59:2076-2080. [PubMed: 1431895]

Sam P, Justice JB Jr. Effect of general microdialysis-induced depletion of extracellular dopamine. Anal. Chem 1996;68:724-728. [PubMed: 8779439]

Sandberg M, Lindstrom S. Amino acids in the dorsal lateral geniculate nucleus of the cat: Collection in vivo. J. Neurosci. Methods 1983;9:65-74. [PubMed: 6138479]

Sato Y, Shibanoki S, Sugahara M, Ishikawa K. Measurement and pharmacokinetic analysis of imipramine and its metabolite by brain microdialysis. Br. J. Pharmacol 1994;112:625-629. [PubMed: 8075879]

Sauerwein H, Miyamoto A, Gunther J, Meyer HH, Schams D. Binding and action of insulin-like growth factors and insulin in bovine luteal tissue during the oestrous cycle. J. Reprod. Fertil 1992;96:103115. [PubMed: 1432941]

Saunders RC, Kolachana BS, Weinberger DR. Local pharmacological manipulation of dopamine in prefrontal cortex and caudate in the rhesus monkey: An in vivo microdialysis study. Exp. Brain Res 1993;98:44-52. [PubMed: 8013591]

Scheller D, Kolb J. The internal reference technique in microdialysis: A practical approach to monitoring dialysis efficiency and to calculating tissue concentration from dialysate samples. J. Neurosci. Methods 1991;40:31-37. [PubMed: 1795551]

Scheller D, Kolb J, Tegtmeier F, Lehmenkuhler A. Extracellular changes of inorganic phosphate are different during spreading depression and global cerebral ischemia of rats. Neurosci. Lett 1992;141:269-272. [PubMed: 1436648]

Scheyer RD, During MJ, Spencer DD, Cramer JA, Mattson RH. Measurements of carbamazepine and carbamazepine epoxide in the human brain using in vivo microdialysis. Neurology 1994a;44:14691472. [PubMed: 8058151]

Scheyer RD, During MJ, Hochholzer JM, Spencer DD, Cramer JA, Mattson RH. Phenytoin concentrations in the human brain: An in vivo microdialysis study. Epilepsy Res 1994b;18:227232. [PubMed: 7805644]

Shimizu N, Hori T, Nakane H. An interleukin-1 $\beta$-induced noradrenaline release in the spleen is mediated by brain corticotropin-releasing factor: An in vivo microdialysis study in conscious rats. Brain Behav. Immun 1994;8:14-23. [PubMed: 8003768]

Siragy HM. Endothelium-derived relaxing factor modulates renal interstitial cycle GMP. J. Cardiovasc. Pharmacol 1992;20:S163-S165. [PubMed: 1282958]

Siragy HM, Jaffa AA, Margolius HS. Stimulation of renal interstitial bradykinin by sodium depletion. Am. J. Hypertension 1993;6:863-866.

Sjoberg P, Olofsson IM, Lundqvist T. Validation of different microdialysis methods for the determination of unbound steady-state concentrations of theophylline in blood and brain tissue. Pharm. Res 1992;9:1592-1598. [PubMed: 1488403]

Smith AD, Olson RJ, Justice JB Jr. Quantitative microdialysis of dopamine in the striatum: Effect of circadian variation. J. Neurosci. Methods 1992;44:33-41. [PubMed: 1279321]

Spanagel R, Herz A, Shippenberg TS. The effects of opioid peptides on dopamine release in the nucleus accumbens: An in vivo microdialysis study. J. Neurochem 1990;55:1734-1740. [PubMed: 1976759]

Specialle C, Ungerstedt U, Schwarcz R. Effect of kynurenine loading on quinolinic acid production in the rat: Studies in vitro and in vivo. Life Sci 1988;43:777-786. [PubMed: 2970571]

Stahle L, Sebersvard S, Ungerstedt U. A comparison between three methods for estimating the extracellular concentration of endogenous and exogenous compounds by microdialysis. J. Pharmacol. Methods 1991;25:42-52.

Steele MK, Stephenson KN, Meredith JM, Levine JE. Effects of angiotensin II on LHRH release as measured by in vivo microdialysis of the anterior pituitary gland of conscious female rats. Neuroendocrinology 1992;55:276-281. [PubMed: 1501758]

Stone EA, John SM. Stress induced increases in extracellular levels of cyclic AMP in rat cortex. Brain Res 1992;597:144-147. [PubMed: 1335818] 
Taylor DL, Davies SE, Obrenovitch TP, Urenjak J, Richards DA, Clark JB, Symon L. Extracellular $N$ acetylaspartate in the rat brain: In vivo determination of basal levels and changes evoked by high $\mathrm{K}^{+}$J. Neurochem 1994;62:2233-2240. [PubMed: 8189231]

Thompson AC, Justice JB Jr, McDonald JK. Quantitative microdialysis of neuropeptide Y. J. Neurosci. Methods 1995;60:189-198. [PubMed: 8544479]

Tossman U, Wieloch T, Ungerstedt U. Gamma-aminobutyric acid and taurine release in the striatum of the rat during hypoglycemic coma, studied by microdialysis. Neurosci. Lett 1985;62:231-235. [PubMed: 4088534]

Tossman U, Jonsson G, Ungerstedt U. Regional distribution and extracellular levels of amino acids in rat central nervous system. Acta Physiol. Scand 1986;127:533-545. [PubMed: 2875604]

Tsai G, Forloni G, Robinson MB, Stauch BL, Coyle JT. Calcium-dependent evoked release of $N-\left[{ }^{3} \mathrm{H}\right]$ acetylaspartylglutamate from the optic pathway. J. Neurochem 1988;51:1956-1959. [PubMed: 3183672]

Ungerstedt, U. Measurement of neurotransmitter release by intracranial dialysis. In: Marsden, CA., editor. Measurement of Neurotransmitter Release In Vivo. New York: John Wiley \& Sons; 1984. p. 81-105.

Ungerstedt U, Pycock C. Functional correlates of dopamine neurotransmission. Bull. Schweitz. Akad. Med. Wiss 1974;1278:1-13.

Ungerstedt, U.; Herrera-Marchintz, M.; Jungnelius, U.; Stahle, L.; Tossman, U.; Zetterstrom, T. Dopamine synaptic mechanisms reflected in studies combining behavioral recordings and brain dialysis. In: Kotisaka, M., editor. Advances in Dopamine Research. Elmsford, N.Y.: Pergamon Press; 1982. p. 219-231.

Van Wylen DGL, Park T, Rubio R, Berne RM. Increases in cerebral interstitial fluid adenosine concentration during hypoxia, local potassium infusion, and ischemia. J. Cereb. Blood Flow Metab 1986;6:522-528. [PubMed: 3760038]

Vinson PN, Justice JB Jr. Effect of neostigmine on concentration and extraction fraction of acetylcholine using quantitative microdialysis. J. Neurosci. Methods 1997;73:61-67. [PubMed: 9130679]

Wages SA, Church WH, Justice JB. Sampling considerations for on-line microbore liquid chromatography of brain dialysis. Anal. Chem 1986;58:1649-1656. [PubMed: 3752502]

Wang Y, Sawchuk RJ. Zidovudine transporter in the rabbit brain during intravenous and intracerebroventricular infusion. J. Pharm. Sci 1995;84:871-876. [PubMed: 7562440]

Westerink, BHC.; Justice, JB, Jr. Microdialysis compared with other in vivo release models. In: Robinson, TE.; Justice, JB., Jr, editors. Microdialysis in the Neurosciences. New York: Elsevier Science Publishing; 1991. p. 23-43.

Westerink BHC, Damsma G, Rollema H, de Vries JB, Horn AS. Scope and limitations of in vivo brain dialysis: A comparison of its application to various neurotransmitter systems. Life Sci 1987;41:1763-1776. [PubMed: 2889121]

Westerink BHC, Hofsteede HM, Damsma G, de Vries JB. The significance of extracellular calcium for the release of dopamine, acetylcholine and amino acids in conscious rats, evaluated by brain microdialysis. Naunyn-Schmiedeberg's Arch. Pharmacol 1988;337:373-378.

Wood, JH.; Wood, JH., editors. Neurobiology of cerebrospinal fluid, Vol. 1. New York: Plenum; 1980.

Wright IK, Upton N, Marsden CA. Effects of established and putative anxiolytics on extracellular 5-HT and 5-HIAA in the ventral hippocampus of rats during behavior on the elevated X-maze. Psychopharmacology 1992;109:338-346. [PubMed: 1285416]

Yoshimoto K, Komura S, Kawamura K. Occurrence in vivo of 5-hydroxytryptophol in the brain of rats treated with ethanol. Alcohol 1992;27:131-136.

Yue TL, Gu JL, Lysko PG, Cheng HY, Barone FC, Feursteun G. Neuroprotective effects of phenyl-tbutylnitrone in gerbil global brain ischemia and in cultured rat cerebellar neurons. Brain Res 1992;574:193-197. [PubMed: 1353399]

Zetterstrom T, Sharp T, Collin AK, Ungerstedt U. In vivo measurement of extracellular dopamine and DOPAC in the rat striatum after various dopamine-releasing drugs: Implications for the origin of extracellular DOPAC. Eur. J. Pharmacol 1988;148:327-334. [PubMed: 3384000] 

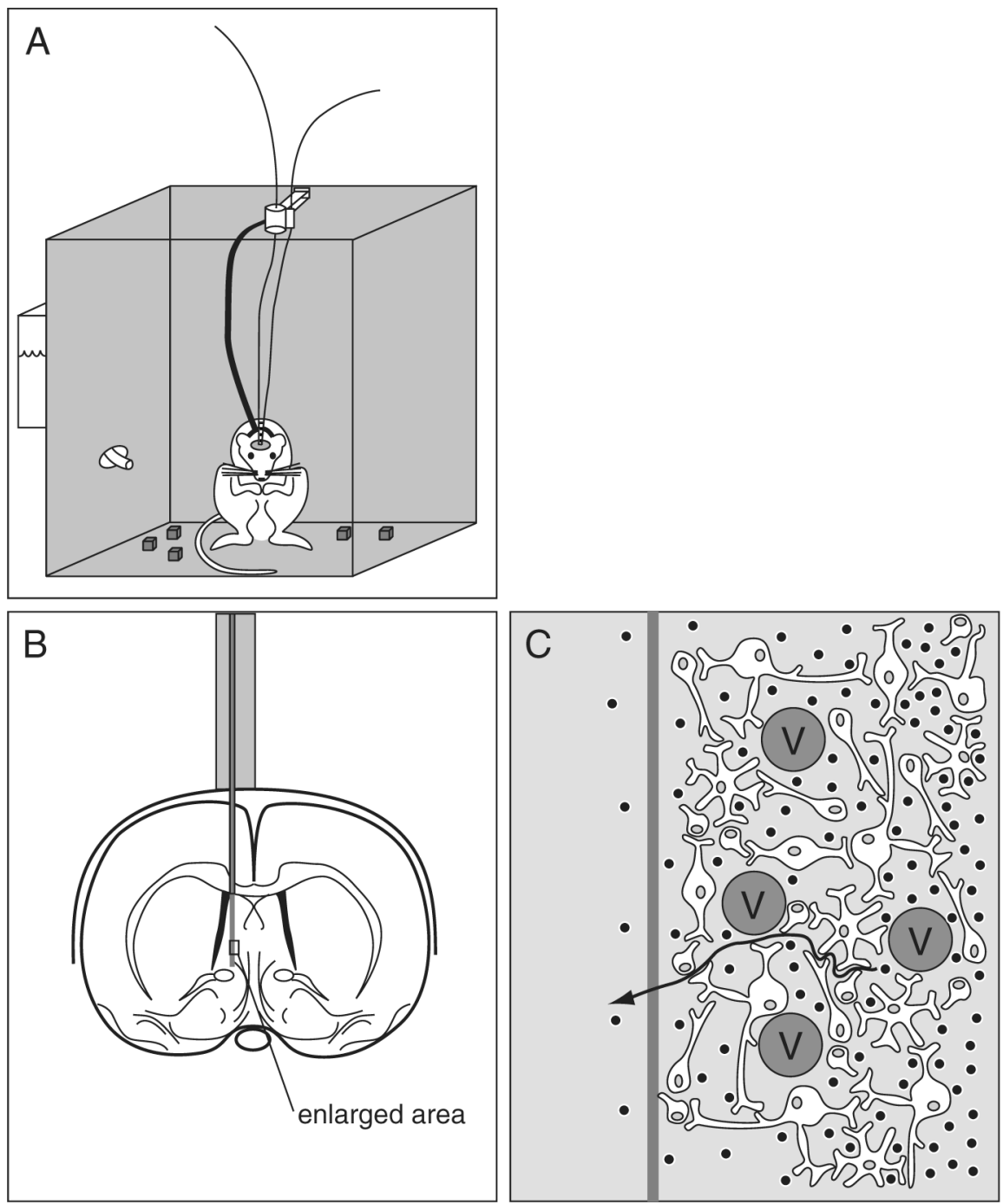

Figure 7.1.1.

Representation of the "inside view" of a microdialysis probe. The microdialysis probe, which consists of an inflow and outflow tubing (A) separated by tubing made of dialysis membrane, is implanted surgically into a specific area within the brain (B). The enlarged view (C) illustrates the complex composition of the fluid through which analytes (black dots) must diffuse to get to the microdialysis probe. The presence of impermeable cells such as blood vessels $(V)$ reduces the fluid volume surrounding the probe and increases the diffusional path (arrow) of analytes moving toward the probe. The net effect is a decreased diffusivity in this phase. 


\section{Compounds Analyzed by Microdialysis}

Table 7.1.1

\begin{tabular}{|c|c|}
\hline Substance $^{a}$ & Reference \\
\hline$N$-acetylaspartate & Taylor et al., 1994 \\
\hline $\mathrm{N}-\left[^{3} \mathrm{H}\right]$ acetylaspartylglutamate & Tsai et al., 1988 \\
\hline Acetylcholine & Consolo et al., 1987; Damsma et al., 1987 \\
\hline Adenosine & Chen et al., 1992; Lonnroth et al., 1989 \\
\hline Ascorbate & Hallstrom et al., 1989 \\
\hline Aspartate, D- $\left[{ }^{3} \mathrm{H}\right]$ aspartate & Kendrick et al., 1988; Nielsen et al., 1989 \\
\hline Bradykinin & Siragy et al., 1993 \\
\hline Carbamazepine, carbamazepine epoxide & Scheyer et al., 1994a \\
\hline Cyclic AMP & Stone and John, 1992 \\
\hline 5-S-cysteinyldopa & Blomquist et al., 1991 \\
\hline 3,4-dihydroxyphenylethyleneglycol & Itoh et al., 1990 \\
\hline Dopamine and metabolites & Imperato and Di Chiara, 1984; Zetterstrom et al., 1988 \\
\hline Eicosanoid & Callaghhan et al., 1994 \\
\hline Endogenous opioid peptides & Maidment et al., 1989 \\
\hline Epinephrine & Dev et al., 1992 \\
\hline Ethanol levels & Dev et al., 1992 \\
\hline Follicle stimulating hormone & Lincoln, 1992 \\
\hline GABA & Bourdelais and Kalivas, 1992 \\
\hline Glucose & de Boer et al., 1992 \\
\hline Glutamate & Dietze and Kushinsky, 1992 \\
\hline Glutathione and other thiols & Dizdar et al., 1991 \\
\hline Histamine & Petersen et al., 1992a,b \\
\hline 5-hydroxyindoleacetic acid & Guadalupe et al., 1992 \\
\hline 5-hydroxytryptophol & Yoshimoto et al., 1992 \\
\hline Hypoxanthine & Hagberg et al., 1987 \\
\hline Imipramine and metabolites & Sato et al., 1994 \\
\hline Inorganic phosphate & Scheller et al., 1992 \\
\hline Inosine & Hagberg et al., 1987 \\
\hline Kynurenic acid & Russi et al., 1992 \\
\hline Lactate & Hallstrom et al., 1989; Okuda et al., 1992a,b \\
\hline Levodopa, DA, and their metabolites & Deleu et al., 1993 \\
\hline LHRH & Steele et al., 1992 \\
\hline Melatonin & Hasegawa and Ebihara, 1992 \\
\hline Methotrexate & Matsuyama et al., 1994 \\
\hline 3-O-methyldopa & Deleu et al., 1993 \\
\hline MHPG & Kubota et al., 1993 \\
\hline Neurokinin A & Lindefors et al., 1989a \\
\hline Neuropeptide Y & Lambert et al., 1994 \\
\hline Neurotensin & During et al., 1992 \\
\hline Norepinephrine & Abercrombie and Zigmond, 1989 \\
\hline Oxidation of ${ }^{14} \mathrm{C}$-labeled substrates to ${ }^{14} \mathrm{CO}_{2}$ & Huang et al., 1993 \\
\hline Oxytocin & Kendrick et al., 1988 \\
\hline L-phenylalanine & Brust and Diemer, 1990 \\
\hline Phenytoin & Scheyer et al., 1994b \\
\hline Progesterone & Miyamoto and Schams, 1991 \\
\hline Prolactin & Lincoln, 1992 \\
\hline Propranolol & Lonnroth et al., 1991 \\
\hline Pyruvate & Hallstrom et al., 1989 \\
\hline Quinolinic acid & Specialle et al., 1988 \\
\hline Salicylic acid & Chiueh et al., 1992 \\
\hline Serotonin and metabolites & Wright et al., 1992 \\
\hline Somatostatin & Lahtinen et al., 1992 \\
\hline Substance P & Linderoth et al., 1992 \\
\hline Taurine & Tossman et al., 1985 \\
\hline Theophylline & Tossman et al., 1985 \\
\hline Valproic acid & Golden et al., 1993 \\
\hline Vasopressin & Ota et al., 1992 \\
\hline Xanthine & Hagberg et al., 1987 \\
\hline Zidovudine & Wang and Sawchuk, 1995 \\
\hline
\end{tabular}

${ }^{a}$ GABA, $\gamma$-aminobutyric acid; DA, dopamine; LHRH, luteinizing hormone releasing hormone; MHPG, 4-hydroxy-3-methylphenylglycol. 
Tissues Analyzed by Microdialysis

Table 7.1.2

\begin{tabular}{ll}
\hline Organ system & Reference \\
\hline Adipose tissue & Hallstrom et al., 1989 \\
Adrenal glands & Kuzmin et al., 1990 \\
Blood & Sjoberg et al., 1992 \\
Brain & Hallstrom et al., 1989 \\
Heart & Kuzmin et al., 1992 \\
Ileum & Fukui et al., 1993 \\
Kidney & Siragy, 1992 \\
Liver & Okuda et al., 1992b \\
Luteal tissue & Sauerwein et al., 1992 \\
Muscle & Hallstrom et al., 1989 \\
Pancreas & Jonsson et al., 1992 \\
Retina & Louzada-Junior et al., 1992 \\
Skin & Petersen et al., 1992b \\
Spinal cord & Linderoth et al., 1992 \\
Spleen & Shimizu et al., 1994 \\
Subcutaneous tissue & Deleu et al., 1993 \\
Uterus & Nordenvall et al., 1989 \\
& \\
\hline
\end{tabular}




\section{Species Analyzed by Microdialysis}

\section{Table 7.1.3}

\begin{tabular}{|c|c|}
\hline Species & Reference \\
\hline \multicolumn{2}{|l|}{ Carnivoran } \\
\hline Cat & Linderoth et al., 1992 \\
\hline Dog & Kuzmin et al., 1992 \\
\hline \multicolumn{2}{|l|}{ Primate } \\
\hline Baboon & Khan-Dawood et al., 1994 \\
\hline Common marmoset & Nomoto et al., 1994 \\
\hline Cynomolgus monkey & Ljungdahl-Stahle et al., 1992 \\
\hline Human & Petersen et al., 1992a,b \\
\hline Rhesus monkey & Saunders et al., 1993 \\
\hline \multicolumn{2}{|l|}{ Rodentian } \\
\hline Gerbil & Yue et al., 1992 \\
\hline Guinea pig & Callaghhan et al., 1994 \\
\hline Mouse & Rollema et al., 1989 \\
\hline Rat & Wright et al., 1992 \\
\hline Siberian hamster & Glass et al., 1992 \\
\hline \multicolumn{2}{|l|}{ Artiodactylan } \\
\hline Cow & Einspanier et al., 1990 \\
\hline Goat & Hashizume et al., 1995 \\
\hline Pig & Jonsson et al., 1992 \\
\hline Sheep & Kendrick et al., 1989 \\
\hline \multicolumn{2}{|r|}{ 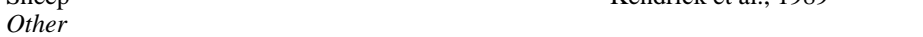 } \\
\hline Horse & Ingvast-Larsson et al., 1991 \\
\hline Pigeon & Hasegawa and Ebihara, 1992 \\
\hline Rabbit & Wang and Sawchuck, 1995 \\
\hline Rainbow trout & Hylland et al., 1995 \\
\hline
\end{tabular}

